\title{
INICIATIVAS DE DESARROLLO RURAL EN LAS MONTAÑAS DEL PAÍS VASCO'
}

\author{
Eugenio RUIZ URRESTARAZU - Rosario GALDÓS URRUTIA - María \\ Cruz PORCAL GONZALO \\ Universidad del País Vasco
}

Recibido: 01/03/2010

Aceptado: 02/04/2010

RESUMEN: El objetivo se centra en analizar y valorar iniciativas que puedan colaborar al desarrollo rural en áreas de montaña del País Vasco. A partir de un modelo común de desarrollo se utiliza una metodología inductiva, basada en el estudio de casos seleccionados, a través de iniciativas e indicadores pertenecientes a actuaciones de desarrollo económico en los sectores agrario, industrial y terciario. Las conclusiones confirman que los resultados de dicha iniciativas son dispares en función del sector económico y del territorio concernido.

PALABRAS CLAVE: desarrollo rural, montañas, País Vasco.

\section{INITIATIVES FOR RURAL DEVELOPMENT IN THE MOUNTAIN AREAS OF THE} BASQUE COUNTRY

ABSTRACT: The focus centres around analysing and evaluating initiatives that can help rural development in mountain areas of the Basque Country. Starting with a common development model, a method of inductive reasoning is used based on the study of selected cases through initiatives and indicators pertaining to economic development activities within the agricultural, industrial and tertiary sectors. The findings confirm that the results of such initiatives are disparate in terms of the economic sector and the territory concerned.

KEY WORDS: rural development, mountains, the Basque Country.

PROJETS DE DÉVELOPPEMENT RURAL DES ZONES MONTAGNEUSES DU PAYS BASQUE

RÉSUMÉ: L'objectif majeur est d'analyser et de valoriser des initiatives permettant de contribuer au développement rural dans les zones de montagne du Pays Basque. D'après un modèle commun de développement, on utilise une méthodologie inductive basée dans l'étude de

\footnotetext{
${ }^{1}$ Este artículo se enmarca en el Proyecto de Investigación Dinámica socioeconómica y articulación territorial de las áreas de montaña de la Cordillera Cantábrica y Pirineos Atlánticos. Experiencia y orientaciones para el desarrollo sostenible y la cohesión (SEJ2007-67655-C05-03) financiado por el Ministerio de Educación y Ciencia y también en el Proyecto de Investigación Terciarización de las montañas en la Comunidad Autónoma Vasca y en Navarra: procesos de desarrollo turístico y sostenibilidad territorial (EHU08/60) financiado por la Universidad del País Vasco (U.P.V./E.H.U.).
} 
cas sélectionnés à travers des initiatives et des indicateurs appartenant à des actions de développement économique dans les secteurs agraire, industriel et tertiaire. Les conclusions confirment que les résultats de ces initiatives sont dissemblables selon le secteur économique et le territoire concernés.

MOTS-CLÉS: Développement rural, montagnes, Pays Basque.

INCIATIVAS DE DESEMVOLVIMENTO RURAL NAS MONTANHAS DO PAIS VASCO

RESUMO: O objectivo concentra-se na análise e avaliação de iniciativas que possam contribuir para o desenvolvimento rural em áreas de montanha do País Vasco. A partir de um modelo comum de desenvolvimento utiliza-se uma metodologia indutiva, baseada no estudo de casos seleccionados, através de iniciativas e indicadores pertencentes a acções de desenvolvimento económico nos sectores agrário, industrial e terciário. As conclusões confirmam que os resultados dessas iniciativas são díspares em função do sector económico e do território abrangido.

PALAVRAS CHAVE: desenvolvimento rural, montanhas, País Vasco.

\section{INTRODUCCIÓN Y OBJETIVOS}

Desde hace más de veinte años, el concepto y la práctica del desarrollo rural han ido ganando protagonismo en la investigación, en las políticas y normativas de los diferentes ámbitos administrativos y en la actuación de los agentes territoriales. Pero es a partir de 1996, cuando a final de año se aprueba la Declaración de Cork, que el desarrollo rural, al que se le añade de manera ya perdurable el calificativo de sostenible, se erige en el eje central de cualquier plan o actuación sobre estos espacios (NOGALES, 2006). Pasa a convertirse en principio fundamental de toda política rural (MAITÏA, F., 2006). Basta recordar algunos de los instrumentos básicos que en la actualidad o dentro de un plazo inmediato enmarcan las actuaciones en espacios rurales tanto en España como en el País Vasco. En el primer caso la Ley 45/2007 para el desarrollo sostenible del medio rural establece el marco general de cualquier iniciativa en este campo y las medidas generales para conseguir dicho desarrollo. Tal como se especifica en su preámbulo, se trata de una Ley con orientación territorial que deberá ser aplicada bajo criterios y directrices propios de la ordenación territorial. Asimismo las medidas y acciones previstas en ella son de carácter multisectorial y medioambiental sobre un medio rural cada vez más diversificado y multifuncional. También se enfatiza la necesidad de lograr un elevado grado de gobernanza. Aunque en su articulado no se define el concepto de desarrollo rural sostenible como tal, sí que puede deducirse dicho concepto a través de los objetivos generales que plantea:

a. Mantenimiento y ampliación de la base económica preservando actividades competitivas y multifuncionales y diversificando la economía mediante infraestructuras y equipamientos suficientes y nuevas actividades compatibles con un desarrollo sostenible 
b. Mantenimiento y mejora del nivel de población y del grado de bienestar por medio de unos servicios públicos adecuados que garanticen la igualdad de oportunidades y la no discriminación.

c. Conservación y recuperación del patrimonio y los recursos naturales y culturales.

Cada uno de estos objetivos generales se acompaña de otros más específicos que, aunque no se van a reseñar, ayudan a concretar aún más el alcance que se confiere al desarrollo rural sostenible.

La aplicación práctica de esta Ley se desarrollará a través de un Programa de Desarrollo Rural Sostenible que en el momento de escribir estas líneas no se encuentra aún aprobado pero para el que se prevé su vigencia durante el quinquenio 2010-2014. Las actuaciones contenidas en la versión preliminar se ordenan en cinco ejes que de nuevo contienen la esencia de lo que debe entenderse como desarrollo rural sostenible:

1) Actividad económica y empleo;

2) Infraestructuras y equipamientos básicos;

3) Servicios y bienestar social;

4) Medio ambiente;

5) Cooperación, innovación e igualdad

En el caso vasco la Ley 10/1998, de 8 de abril, de Desarrollo Rural define el marco de juego de futuras actuaciones $y$, entre otras determinaciones, por lo que aquí más interesa, expone el contenido que deberán incluir los Programas de Desarrollo Rural de las comarcas rurales. Por el Decreto 22/2003 del Gobierno Vasco, de 25 de junio, se aprueban los Programas de Desarrollo Rural de las siguientes comarcas: Arratia-Nervión, Encartaciones, Tolosaldea, Urola-Kosta, Cantábrica Alavesa, Estribaciones del Gorbea, Llanada Alavesa, Montaña Alavesa, Rioja Alavesa y Valles Alaveses (BOPV n $\left.{ }^{\circ} 73,11 / 04 / 2003\right)$. Estos programas establecen los distintos ámbitos sectoriales y de actuación administrativa de acuerdo con las directrices emanadas de la anterior Ley. Estos ámbitos son los siguientes: agricultura y silvicultura; diversificación del tejido económico y creación de empleo; turismo; educación y cultura; sanidad; vivienda; infraestructuras; ordenación del territorio; medio ambiente.

Por último otro documento actual de referencia es el Programa de Desarrollo Rural del País Vasco 2007-2013 cuya versión original de 2007 fue aprobada por la Comisión Europea mediante Decisión C-704 de 15 de febrero de 2008 y modificada y también aprobada el 9 de julio de 2009. Este Programa se ha adaptado a las directrices fijadas por el Plan Estratégico Nacional de Desarrollo Rural 2007-2013 y por el Marco Nacional de Desarrollo Rural 2007-2013, 
derivado del anterior. El Programa Vasco se estructura en torno a cuatro ejes de actuación:

1) Aumento de la competitividad del sector agrícola y forestal;

2) Mejora del medioambiente y del entorno rural;

3) Calidad de vida en las zonas rurales y diversificación de la economía;

4) Enfoque LEADER

Enmarcado dentro de estos enfoques sobre desarrollo rural, muy coincidentes entre sí, el objetivo de este trabajo consiste en analizar y valorar iniciativas que puedan colaborar al desarrollo rural en áreas de montaña del País Vasco. El proceso que se ha seguido, así como sus limitaciones, se explican en el siguiente epígrafe.

\section{METODOLOGÍA}

Si en el anterior apartado se ha concedido un destacado protagonismo a los instrumentos de desarrollo rural es porque han sido utilizados a la vez como elementos metodológicos. En los distintos programas mencionados se enumeran y especifican ejes y actuaciones que deben ser implementados para lograr avances en el desarrollo de las áreas rurales. Teniendo presente el elevado número de actuaciones que se ofrecen, para este trabajo se han seleccionado de forma sectorial las que hacen referencia a iniciativas de desarrollo económico, en concreto las que afectan a los sectores agrario, industrial y terciario. De dichos listados sectoriales, muy similares entre sí, se ha realizado una síntesis cuyos componentes sirvan de indicadores de análisis. El listado inicial de iniciativas abarcaba las siguientes actuaciones:

A) Iniciativas para el mantenimiento de la actividad agraria: 1. Mejora de la rentabilidad de las explotaciones agrarias y ganaderas; 2. Limitar la fragmentación de las explotaciones agrarias; 3 . Potenciar y favorecer la diversificación de cultivos; 4. Potenciar la mejora de la gestión forestal; 5. Potenciación del papel de la mujer en el sector; 6. Favorecer el código de buenas prácticas; 7 . Diferenciación de los productos de la comarca; 8. Favorecer la transmisión de terrenos a jóvenes agricultores

B) Iniciativas para el desarrollo industrial: 1. Atracción de empresas industriales a la comarca; 2 . Oferta y ocupación de suelo industrial

C) Iniciativas de terciarización y promoción del turismo: 1. Recursos, elementos y servicios; 2 . Mejora de la oferta turística; 3 . Ampliación de la infraestructura comercial 
Sobre este listado inicial de actuaciones hay que hacer un par de precisiones. En primer lugar, que no se trata en ningún momento de evaluar los resultados de los programas ya que el tiempo transcurrido desde su aplicación resulta insuficiente $y$, aunque en algunos programas no lo sea, no existe información temporal disponible para todos los indicadores adaptada al período de vigencia, problema que en temas relativos al sector primario se subsanará con la publicación del próximo Censo Agrario de 2009. En segundo lugar, el anterior listado sólo ha servido de referencia ya que ha tenido que ser modificado en parte o limitado por las razones que se exponen a continuación. Para cada iniciativa era preciso utilizar indicadores que midiesen el grado de ejecución de las mismas y que pudiesen ser utilizados al mismo tiempo para valorar su contribución al desarrollo rural. De forma paralela se han establecido unos criterios de selección de dichos indicadores:

a) Deben aportan una información cuantitativa de modo que sean fácilmente comparables entre las diferentes áreas de estudio

b) La información ha de obtenerse de fuentes directamente disponibles

c) La información debe ser la misma para todas las áreas de estudio con el fin de establecer las comparaciones pertinentes

d) La información debe permitir en la mayor parte de los casos posibles la realización de un estudio temporal de su evolución reciente

Por tanto la información se somete a un doble filtro analítico: diacrónico y territorial. De este modo es factible valorar la evolución experimentada en cada área de estudio y compararla con la de las otras áreas. En último término ha sido la disponibilidad de fuentes de información, sometida a los criterios mencionados, el factor que ha determinado la lista final de iniciativas analizables. En definitiva se ha empleado una metodología inductiva pero enmarcada en un mismo modelo de desarrollo rural.

Otra nota metodológica importante, que ya ha sido comentada de forma implícita, ha consistido en la limitación territorial del área de análisis y comprobación. Aunque el objetivo general atañe a las montañas del País Vasco se ha optado por aplicarlo a áreas territoriales seleccionadas que fuesen representativas de su variedad medioambiental, socioeconómica y de organización espacial.

\section{LA SELECCIÓN DE LOS ESTUDIOS DE CASO}

El País Vasco es un territorio de reducida extensión, $7.234,8 \mathrm{~km}^{2}$, y montañoso en su mayor parte. Siguiendo los criterios que se especifican en las líneas siguientes, el $64,5 \%$ de su extensión cabe insertarla dentro de la calificación de 
área de montaña, siempre dentro de los parámetros físicos que se asignan a la montaña media europea. De los 251 municipios que componen esta comunidad autónoma, 153, el 69\%, se encuentran dentro de zonas catalogadas de montaña.

En un trabajo previo de RUIZ y GALDós (2008) la diversidad ambiental de la montaña vasca se resume en tres categorías: la montaña atlántica, la montaña subatlántica y submediterránea y la montaña mediterránea.

Esta clasificación de base física fue completada en un artículo posterior de los mismos autores en el que se establecieron unos criterios que han sido utilizados aquí para delimitar las áreas de montaña del País Vasco, así como para establecer la tipología de las mismas (GALDÓs y RUIZ, 2008). El punto de partida, posteriormente modificado, de dicha delimitación es la declaración de Zonas de Agricultura de Montaña (ZAM) que obedecen a los criterios de altitud y pendiente que se establecieron en la Ley 25/1982 de Agricultura de Montaña. En tal declaración se incluía el $85 \%$ del territorio vasco y el $84,1 \%$ del total de municipios. Pero la delimitación que en este caso interesa no obedece solamente a criterios topográficos, sino que incorpora de manera destacada la componente rural de la montaña con el fin de conseguir el objetivo propuesto. Por este motivo se ha eliminado de la lista de municipios ZAM una serie de ellos que no cumplen los requisitos requeridos de ruralidad. Para esta exclusión se han manejado los siguientes criterios. En primer lugar se han suprimido aquellos municipios que pertenecen a las áreas metropolitanas de Bilbao y San Sebastián; en segundo término se han eliminado los municipios litorales ya que su dinámica socioeconómica les aleja de lo rural para incorporarlos dentro de ámbitos terciarizados; y por último se han suprimido los municipios que cuentan con alguna ciudad media o de marcado carácter industrial. En este último caso se ha empleado un criterio demográfico, al descartarse aquellos que superan los 10.000 habitantes. El resultado final ha sido el resalte de un conjunto montañoso más homogéneo y donde los caracteres rurales permanecen más marcados. Sin embargo bajo esta relativa homogeneidad se sigue encerrando una diversidad medioambiental, paisajística y socioeconómica destacable.

Para lograr catalogar de una forma más objetiva esta diversidad se eligieron una serie de variables económicas, demográficas y espaciales: densidad de población; número de habitantes; tasa de crecimiento; índice de vejez; razón de masculinidad; proporción de población ocupada en la agricultura; aportación del sector agrario al VAB municipal; aportación del sector industrial al VAB municipal; aportación del sector de servicios al VAB municipal; número de establecimientos industriales; proporción de tierras cultivadas; proporción de la superficie forestal arbolada; porcentaje de superficie construida; proporción de vivienda secundaria (BERGA MONGE, A.). Estas variables fueron tratadas por el método Cluster para conseguir una serie de agrupaciones o conglomerados de 
municipios de montaña. El resultado ha sido la plasmación de tres conglomerados que en buena medida coinciden con las categorías ambientales de montaña antes mencionadas: montaña atlántica, montaña industrializada y montaña subatlántica y submediterránea. Sus caracteres concretos pueden ser consultados en el último artículo citado.

La diversidad interna de la montaña vasca se quiere representar en tres casos de estudio, representativos de dicha variedad. Se han seleccionado áreas espacialmente conjuntas compuestas por municipios que comparten algún macizo montañoso sobresaliente. Se trata pues de áreas creadas ex profeso que sólo en un caso, el de la Montaña Alavesa, coincide con una comarca establecida. Los otros casos contienen municipios pertenecientes a comarcas diferentes. Las tres áreas seleccionadas son la Montaña Alavesa, el Macizo del Gorbea y el Macizo del Ernio, algunas de cuyas características se exponen a continuación.

Figura 1. Mapa de densidad demográfica municipal de los casos de estudio.

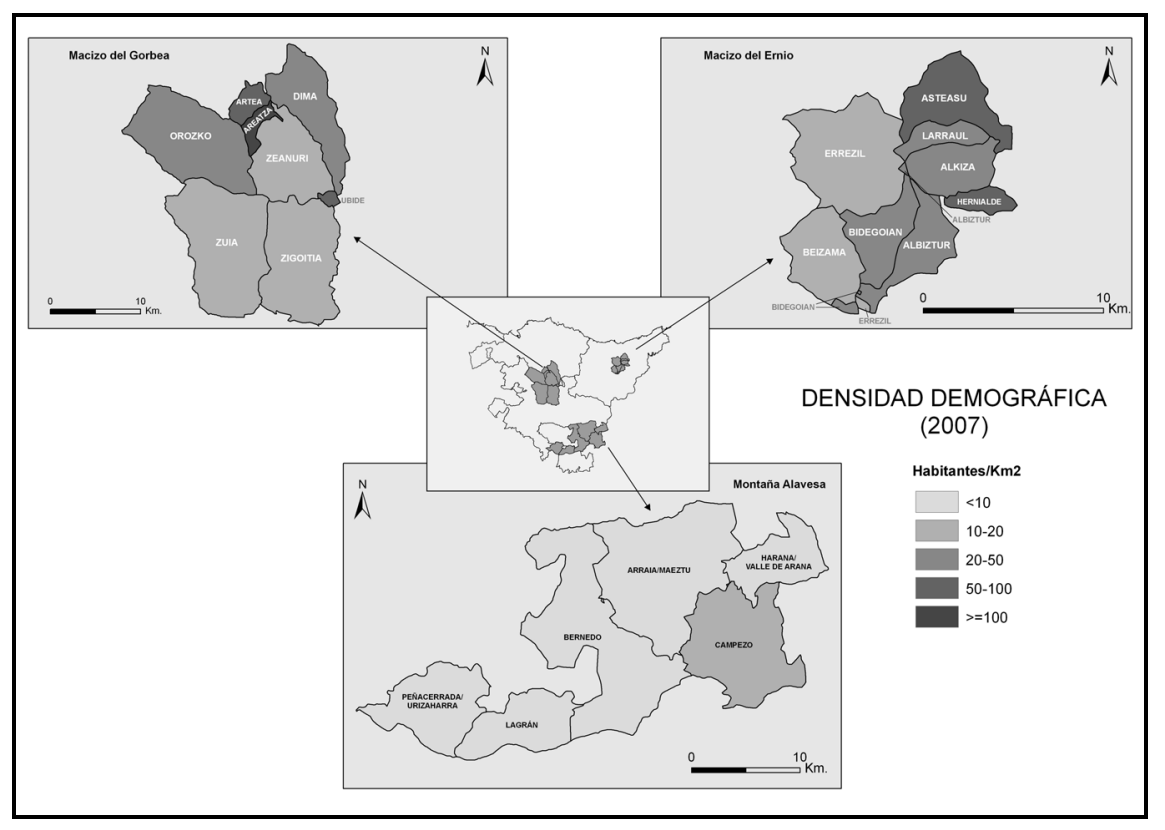

La Montaña Alavesa se localiza en la porción sudoriental de la provincia de Álava, entre las comarcas de la Llanada al norte, la Rioja Alavesa al sur y lindando por el este con Navarra. Abarca una superficie de $481 \mathrm{~km}^{2}$ y en los seis municipios que la componen habitan 3.165 personas. El principal núcleo es Santa Cruz de Campezo con 838 habitantes. Es una zona de montaña media pero de altitud media elevada, alcanzando su máxima cota en los $1.470 \mathrm{~m}$. En su frontera meridional, la Sierra de Ioar-Cantabria-Toloño, se dibuja el límite bio- 
geográfico entre los ambientes atlántico y mediterráneo. Puede ser considerada como una zona rural profunda con las carencias y problemas que ello conlleva. Ha experimentado una evolución demográfica fuertemente regresiva hasta esta primera década del siglo que ha provocado densidades muy bajas, de apenas 10 hab. $/ \mathrm{km}^{2}$ y estructuras demográficas muy desequilibradas con importante presencia de viejos y escasez de jóvenes y de mujeres (GALDÓs, PORCAL y RUIZ, 2009). Su poblamiento se caracteriza por una dispersión en pequeños núcleos, en un paisaje de aldeas, dentro de una dependencia funcional de la capital provincial. La actividad agraria sigue siendo importante, mientras que los servicios se han desarrollado poco. Mantiene una riqueza natural y paisajística notable, con amplias extensiones de propiedad comunal. En su interior alberga el Parque Natural de Izki y, a través de diversos programas de desarrollo rural, se están gestionando variadas iniciativas de diversificación económica y productiva.

Los municipios que componen el Macizo del Gorbea se asientan a caballo entre las dos vertientes, atlántica y mediterránea, de la Cadena Divisoria. Los seis municipios que se localizan en la vertiente atlántica pertenecen a la comarca vizcaína de Arratia-Nervión y los dos alaveses a la de Estribaciones del Gorbea. Posee una extensión de $480,5 \mathrm{~km}^{2}$ y cuenta con 10.667 habitantes, lo que supone una densidad de $34,33 \mathrm{hab} . / \mathrm{km}^{2}$. Sus principales núcleos son Zubiaur en la vertiente atlántica (1.406 habitantes) y Murgia en la mediterránea (1.164). Se corresponde con una topografía de montaña media cuya cota más elevada llega a los $1.475 \mathrm{~m}$. y presenta una disimetría entre las dos vertientes con una altitud media muy superior en la mediterránea. Este macizo representa la transición entre el mundo atlántico y el subatlántico. El primero muestra un paisaje de campiña atlántica con un diseño en mosaico y el segundo se caracteriza por parcelas más amplias dedicadas a prados y dilatadas superficies boscosas de carácter atlántico. Alberga el Parque Natural del Gorbea. Su población ha seguido la evolución ya comentada en la zona anterior, con la particularidad que en este caso la contraurbanización y el rejuvenecimiento poblacional han sido más notorios. El poblamiento vuelve a mostrar la disimetría de las vertientes. En la septentrional atlántica cobra importancia el hábitat diseminado de los caseríos vascos en las laderas, frente a los pequeños pueblos de los fondos de valle. En la vertiente mediterránea desaparece la diseminación a favor de las aldeas, alguna de las cuales ha crecido de manera notable a causa de la inmigración urbana reciente. Cada vertiente depende funcionalmente de sus respectivas capitales provinciales, Bilbao y Vitoria. Se han beneficiado de diversos programas de desarrollo que junto con su evolución demográfica ha logrado diversificar sus actividades productivas con pequeños polígonos industriales, un gran centro comercial y actividades turísticas que conllevan una terciarización apoyada en sus valores medioambientales y sus infraestructuras turísticas. 
El Macizo del Ernio se sitúa en la Cadena Prelitoral de los Montes Vascos dentro de la provincia de Guipúzcoa. Tiene una extensión de $114,17 \mathrm{~km}^{2}, 3.920$ habitantes y una densidad de $34,33 \mathrm{hab} . / \mathrm{km}^{2}$. Cuenta con ocho municipios, seis de ellos en la comarca de Tolosa, dentro de la cuenca del Oria, y otros dos en la comarca de Urola-Costa. El núcleo más poblado es Asteasu con 760 habitantes. Aunque con caracteres de montaña media -el punto más alto no llega a 1.100 m.- destacan sus fuertes desniveles y sus acusadas pendientes. Se corresponde plenamente con el ámbito biogeográfico atlántico que se traduce en un paisaje de campiña con estructura en mosaico en la que se alternan prados de diente y siega, coníferas de repoblación y rodales residuales de bosque atlántico. Vuelve a repetirse la evolución demográfica ya citada, con importantes retrocesos a partir de mediados del siglo pasado y una recuperación en las dos últimas décadas. Si embargo sus estructuras demográficas son más equilibradas. También su poblamiento es el propio del país vasco-atlántico: pequeños pueblos o aldeas en los fondos de valle o en las laderas bajas y caseríos dispersos por el resto del territorio. Es un área de polarización cruzada entre Tolosa y Azpeitia-Azkoitia, al mismo tiempo que su dependencia de San Sebastián también es considerable. Por último destaca por la mayor incidencia de la industria en su tejido productivo, y por encontrarse rodeada a modo de isla por activos corredores urbanoindustriales.

\section{INICIATIVAS PARA EL MANTENIMIENTO DE LA ACTIVI- DAD AGRARIA}

Uno de los objetivos de las políticas de desarrollo rural persigue la conservación y potenciación de las actividades agrarias las cuales "siguen siendo el motor fundamental del mantenimiento del carácter rural en la mayor parte de las zonas rurales de la CAPV" (PROGRAMA DE DESARRollo RURAL DEL PAÍs VASCO 2007-2013, 18), para lo cual se considera indispensable una mejora de las estructuras agrarias que permita la pervivencia económica de las explotaciones agrarias.

La mayoría de las explotaciones agrarias del País Vasco se ven aquejadas de una serie de problemas entre los que destacamos una ausencia de dinamismo empresarial debido a la escasa formación y falta de profesionalización de muchos de los trabajadores del sector, una baja productividad derivada del reducido nivel tecnológico y de unas dimensiones que le impide tratar de forma efectiva los problemas relacionados con la transformación y la inserción en redes de comercialización, y unos costes de producción elevados. No es, por tanto, de extrañar que las políticas de desarrollo rural vengan actuando desde hace unos años con medidas dirigidas al mantenimiento de las explotaciones agrarias y a la mejora de su estructura productiva para lo cual se pretende dotarlas de mayor 
dinamismo e integrarlas en la cadena agroalimentaria. Si se está consiguiendo esta mejora es algo que se pretende constatar analizando las explotaciones de los tres estudios de caso de zonas de montaña del País Vasco, para lo cual se ha considerado conveniente realizar un análisis de la evolución de una serie de parámetros basándonos fundamentalmente en los datos de los Censos Agrarios de 1989 y 1999. Para ofrecer datos actualizados habrá que esperar a la publicación de los resultados del Censo que se ha realizado en los últimos meses del año 2009.

Desde la anterior perspectiva, una mejora de las estructuras de las explotaciones pasa por un incremento de su dimensión superficial y económica y una remodelación de las mismas relacionada con el parcelario, lo que exige una disminución del número de explotaciones y en concreto, la desaparición de las más pequeñas. Al igual que en el conjunto del País Vasco en donde han desaparecido un total de 3.063 explotaciones con tierra, en las tres zonas de estudio se constata una disminución de las mismas aunque no con la misma intensidad. Las mayores pérdidas relativas han tenido lugar en la Montaña Alavesa, afectando dicha disminución a todas las categorías de explotaciones de menos de 50 Ha., con lo cual se ha mejorado sustancialmente el tamaño medio de la explotación que ha pasado de 58 a 69,2 Ha; una evolución similar entre las explotaciones que disponen de SAU ha permitido igualmente un incremento de su tamaño medio, de 13,2 a 26,3 Ha. También se ha producido un aumento del tamaño de la explotación del Macizo del Gorbea, que ha pasado del 20,6 a 24 Ha, gracias sobre todo al comportamiento de los municipios alaveses localizados en tierras de la vertiente mediterránea; esta ampliación de la superficie se ha visto favorecida por la desaparición de un buen número de explotaciones de menos de 5 Ha., lo que de nuevo se repite entre las explotaciones con SAU dando lugar al consiguiente crecimiento de su dimensión media, que ha pasado de 4,8 a 7,9 Ha. En el área del Macizo del Ernio, en donde la desaparición de explotaciones ha sido mínima, la superficie media de las mismas se mantiene sin casi variación pues ha pasado de 14,1 a 14,3 Ha. Además resulta llamativo que en esta zona, en contra de lo deseado, han aumentado las pequeñas explotaciones, las de menos de $5 \mathrm{Ha}$. Lo mismo ha ocurrido entre las explotaciones con SAU cuya superficie media se mantiene estabilizada en 7,3 Ha. En definitiva, los mayores logros se han producido en los municipios que disponían ya de unas explotaciones mejor dimensionadas; es el caso de los municipios de la Montaña Alavesa pero también de aquellos del Macizo del Gorbea que pertenecen a esta misma provincia de Álava, a los que les une una mayor vocación agrícola reflejada en el mayor desarrollo de las superficies labradas. La disminución del número de explotaciones ha venido acompañado en casi todos los municipios alaveses de un incremento de la superficie agraria censada; por el contrario los censos 
registran una pérdida de tierras agrarias en la mayoría de los municipios de la vertiente atlántica.

Cuadro 1. Evolución del número del número de explotaciones con tierra y de la superficie agraria, 1989 y 1999.

\begin{tabular}{lrrrr}
\hline & Explotaciones con tierra & \multicolumn{2}{c}{ Superficie agraria censada } \\
\hline Macizo Gorbea & 1989 & 1999 & 1989 & 1999 \\
Macizo Ernio & 2.022 & 1.822 & 41.553 & 43.716 \\
Montaña Alavesa & 674 & 642 & 9.471 & 9.164 \\
\hline País Vasco & 806 & 712 & 46.720 & 49.268 \\
\hline
\end{tabular}

FuENTE: Ine, Censos Agrarios 1989 y 1999

Aún con todo, las pequeñas explotaciones, las de menos de 5 Ha siguen siendo muy numerosas y tienen un peso relativo muy elevado. Constituyen la categoría más abundante tanto en el Macizo del Gorbea como en la Montaña Alavesa donde representan respectivamente el $49 \%$ y el 37,4\%. En algunos municipios del Macizo del Gorbea, Areatza, Artea y Ubide, representan más de los 2/3 del total de las explotaciones. Las mayores, de más de $50 \mathrm{Ha}$. sólo alcanzan un porcentaje significativo en los municipios alaveses. En la comarca de la Montaña Alavesa representan casi el 23\% y en Ziogitia y Zuia alrededor del 17\%; en los demás municipios del Macizo del Gorbea y en los del Macizo del Ernio los porcentajes se sitúan por debajo del $6 \%$.

A tenor de lo sucedido entre 1982-1989 durante el cual se produjo una disminución notable del número total de parcelas, cabía esperar que en el siguiente intercensal se continuase con esta tendencia que estaba favoreciendo la existencia de un parcelario menos fragmentado. Sin embargo, los datos censales describen un incremento del número total de parcelas, un aumento del número de parcelas por explotación y una disminución o, en el mejor de los casos, una estabilidad del tamaño medio de la parcela. Si en 1989 cada explotación tenía de media 7,1, 6,9 y 12,7 parcelas en el Macizo del Gorbea, en el Macizo del Ernio y en la Montaña Alavesa respectivamente, en 1999 reunían 8,2, 10,1 y 16,3 parcelas. El tamaño medio de la parcela se mantiene estable en el Macizo del Gorbea $(2,9 \mathrm{Ha})$ y ha mermado en el Macizo del Ernio (de 2,1 Ha en 1989 ha pasado a 1,4) y en la Montaña Alavesa (de 4,6 a 4,3 Ha). En este aspecto también se observa una clara diferencia entre las explotaciones de los municipios alaveses de la vertiente mediterránea que poseen parcelas mejor dimensionadas, de 3-4 Ha de media, y las de la vertiente cantábrica, de tamaño más reducido. 
Figura 2. Estructura de las explotaciones con tierra, 1999.

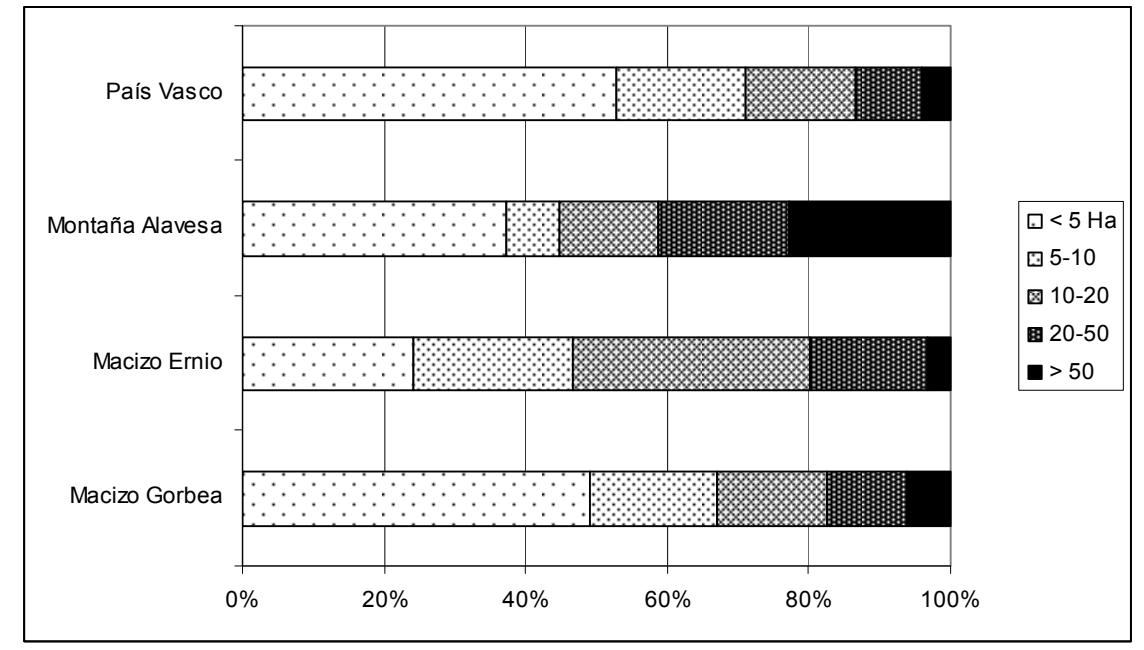

FuENTE: INE, Censo Agrario 1999

En otras áreas de montañas, como la Montaña Cántabra, se ha interpretado que la reestructuración de las explotaciones agrarias se ha producido sobre todo a partir del descenso de la superficie agraria explotada en propiedad y del aumento de las tierras arrendadas (DELGADO et AL., 2004). En las tres zonas analizadas también cabe relacionar los cambios estructurales con las modificaciones detectadas en el régimen de tenencia de la tierra, expresadas en un incremento de la superficie y de la participación relativa de las tierras arrendadas que llega en 1999 a valores del 11-12\% del total censado.

La insuficiente reestructuración física de las explotaciones agrarias no ha facilitado el deseado redimensionamiento económico de las mismas. Su dimensión económica puede analizarse a través de las UDE, unidades de dimensión europea, que definen el tamaño de una explotación agrícola en base a su potencial de valor añadido. En el momento de la realización del Censo de 1999, una UDE correspondía aproximadamente a 1.200 ecus (unidades de cuenta europeas) de margen bruto. La evolución entre 1989 y 1999 muestra diferencias importantes entre las explotaciones localizadas a uno y otro lado de la divisoria de aguas cantábrico-mediterránea. En la vertiente mediterránea crecen las explotaciones de más de 12 UDE y en contrapartida disminuyen las de menor dimensión económica; por el contrario, en la vertiente cantábrica, aumentan, y de forma notable en el Macizo del Ernio, las de menor tamaño económico, las de menos de 2 UDE. Según el Censo de 1999, en la Montaña Alavesa el 39,6\% de las explotaciones eran de más de 12 UDE, porcentaje que se reducía al 14,5\% en el Macizo 
del Ernio y al 7,2\% en el del Gorbea. En esta última zona más de los $2 / 3$ de las explotaciones eran de reducida dimensión económica, inferior a 2 UDE.

Figura 3. Distribución de las explotaciones según UDE, 1999.

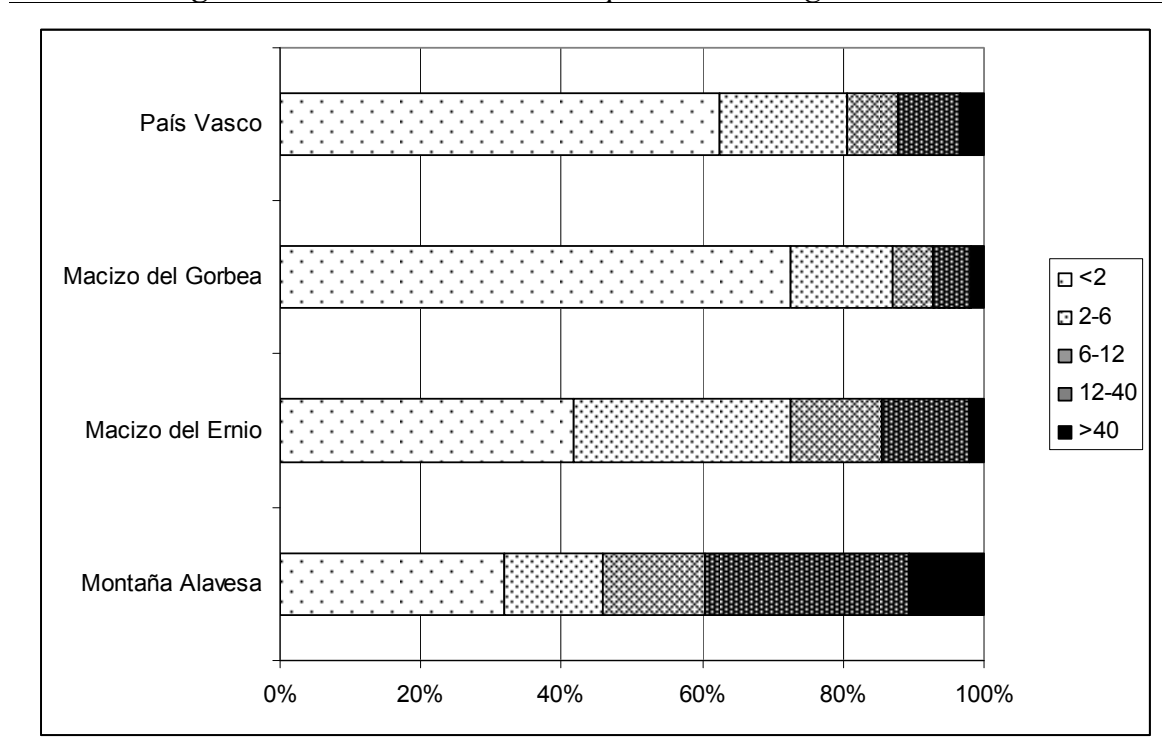

Fuente: Ine, Censo Agrario 1999

Tampoco las medidas encaminadas a la inserción de jóvenes en la agricultura han proporcionado resultados satisfactorios pues no se ha logrado un rejuvenecimiento de la población agraria. Entre 1982 y 1999 ha aumentado la proporción de los titulares de más de 55 años y disminuido la de los menores de 35 años. En 1999 los empresarios más numerosos en las tres zonas de montaña eran los de más de 65 años, en una proporción similar a la del conjunto del País Vasco en el caso de la Montaña Alavesa, mayor en el caso de la zona del Gorbea e inferior en el Macizo del Ernio. Carecemos de datos a escala municipal, pero es de suponer que la mayoría de los titulares de más de 65 años son los jefes de su explotación; al menos esto es lo que indican los valores provinciales y del conjunto del País Vasco lo que revelaría una falta de relevo generacional en muchas de las explotaciones.

El incremento del porcentaje de empresarios en edad de jubilación colabora a la disminución de los que comparten el trabajo en la explotación con otra actividad lucrativa. En 1999, el 70,4\% de los empresarios del Macizo del Ernio se dedicaban exclusivamente a la explotación, porcentaje que se elevaba al $74 \%$ en el Macizo del Gorbea y al 79,3\% en la Montaña Alavesa. 
Figura 4. Estructura por edades de los titulares de las explotaciones agrarias, 1999.

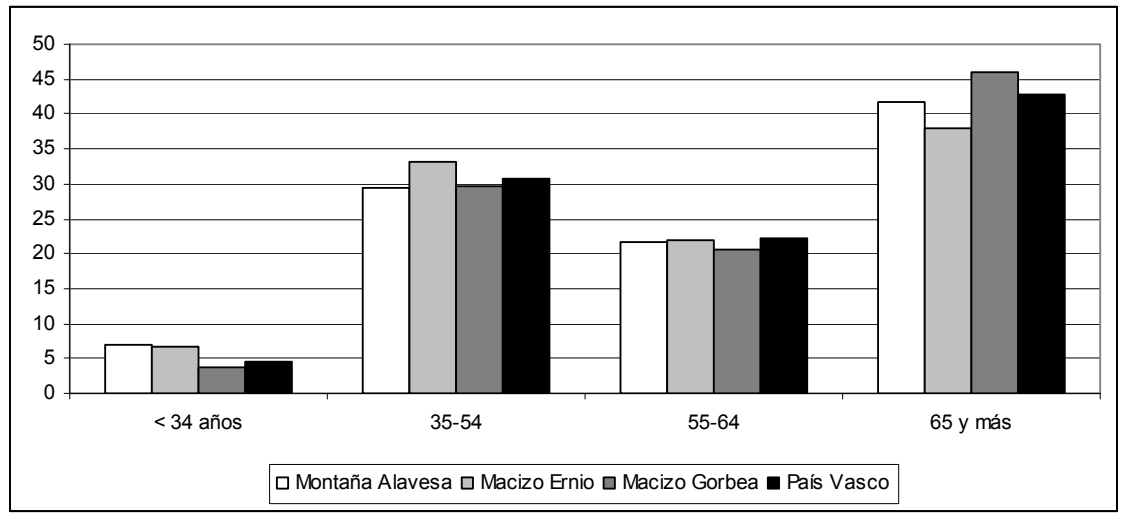

FUENTE: INE, Censo Agrario 1999

La diversificación de la producción agroganadera y el fomento de la producción de calidad se consideran también imprescindibles para el mantenimiento de la actividad agraria. Una vez más nos servimos de los datos censales de 1989 y 1999 para conocer cómo han evolucionado las distintas superficies agrarias en estas áreas de estudio. A grandes rasgos se observa una reducción del terrazgo agrícola allí donde ya era reducido, caso del Macizo del Gorbea y Macizo del Ernio; y un aumento bastante espectacular de las tierras dedicadas a pastos permanentes en el Macizo del Gorbea y en la Montaña Alavesa, el cual coincide con una disminución igualmente notable de la superficie ocupada por especies arbóreas forestales lo que hace sospechar que se trate de distintas formas de catalogar las tierras censadas más que de cambios de uso (DELGADO et AL., 2007), aunque no se descarta un incremento real de los pastizales en estas dos zonas relacionado con un aumento de la cabaña ganadera de carácter extensiva. Datos aportados por el Ministerio de Medio Ambiente y Medio Rural y Marino nos ofrecen una imagen más actualizada de la distribución de las tierras según usos. El común carácter de montaña explicaría ciertas semejanzas en las formas de aprovechamiento de las tierras como es el predominio de los usos forestales los cuales representan en las tres zonas más de la mitad de la superficie, oscilando los porcentajes desde el 55,7\% en el Macizo del Ernio al 63\% de la Montaña Alavesa y el 67,3\% del Macizo del Gorbea. Pero son también áreas con diferentes potenciales y recursos geoecológicos lo que proporciona cierta diversidad en la distribución de las tierras según usos y aprovechamientos. El terrazgo cultivado sólo alcanza una extensión significativa del 19\% en la Montaña Alavesa, siendo su presencia mínima en el Macizo del Ernio y aún más en el Macizo del Gorbea (excepto en el municipio alavés de Zigotia). En contrapartida, los usos pratenses están más desarrollados en los municipios de la vertiente atlánti- 
ca, de mayor especialización ganadera, que en los de la mediterránea; así, en la Montaña Alavesa este uso sólo supone el 4,7\% de su superficie, porcentaje que se eleva al $12 \%$ en el Macizo del Gorbea y a casi el $25 \%$ de las tierras del Macizo del Ernio. Esta superficie de dedicación ganadera se complementa con los pastizales, un uso que alcanza un mayor peso porcentual en la Montaña Alavesa.

Cuadro2. Distribución superficial según grandes grupos de usos (Ha), 2007

\begin{tabular}{lrrr}
\hline & Macizo Gorbea & Macizo Ernio & Montaña Alavesa \\
\hline Cultivos herbáceos & 1.605 & 644 & 8.021 \\
Barbechos* & 190 & 0 & 1.092 \\
Cultivos leñosos & 55 & 88 & 46 \\
Prados naturales & 5.640 & 2.791 & 2.261 \\
Pastizales & 1.704 & 680 & 3.388 \\
Terreno forestal & 32.266 & 6.363 & 30.545 \\
Otras superficies & 6.478 & 866 & 3.144 \\
\hline Superficie total & 47.938 & 11.432 & 48.497 \\
\hline * y otras tierras no ocupadas & \multicolumn{4}{|l}{} \\
FUENTE: Ministerio de Medio Ambiente y Medio Rural y Marino
\end{tabular}

La distribución del terrazgo por grupos de cultivos confirma la vocación ganadera de la montaña atlántica. En el Macizo del Ernio, más del 65\% de las tierras cultivadas se destinan a la obtención de alimento para el ganado, fundamentalmente praderas polifitas, alfalfa y remolacha forrajera; del resto, sólo cabe reseñar la superficie hortícola y la frutícola dedicada ésta casi en exclusiva al manzano. La complejidad es mayor en el área montañosa del Macizo del Gorbea al estar constituido por municipios de la vertiente cantábrica y de la vertiente mediterránea. El escaso terrazgo de los municipios vizcaínos se dedica a cultivar forrajes y de forma secundaria hortalizas y maíz; de los municipios alaveses, es el de Zuia el que ha transformado su tradicional vocación cerealista en otra de primacía ganadera, el que ha atlantizado su terrazgo al especializarlo en el cultivo de forrajes (praderas polifitas principalmente) y hortalizas, asemejándose de este modo al de los municipios de la vertiente cantábrica (RUIZ y GALDÓs, 2008). Por el contrario, el terrazgo de cultivo del municipio de Zigoitia sigue presidido por el cereal (trigo, cebada y avena) el cual rota con otras plantas forrajeras, industriales (remolacha azucarera) y hortícolas. La Montaña Alavesa, la zona que mejor ejemplifica el paisaje de la vertiente mediterránea, conserva unos espacios cultivados de mayor diversidad, en donde el cultivo principal sigue siéndolo el cereal (trigo, avena y en menos medida cebada) que alterna con otros como los forrajeros, la patata, la remolacha azucarera y los hortícolas. 
Cuadro 3. Distribución de la superficie cultivada (Ha), 2007

\begin{tabular}{lrrr}
\hline & Macizo Gorbea & Macizo Ernio & Montaña Alavesa \\
\hline Cereales & 898 & 35 & 6594 \\
Leguminosas & 7 & 16 & 17 \\
Tubérculos & 24 & 9 & 431 \\
Cultivos industriales & 49 & 0 & 210 \\
Cultivos forrajeros & 568 & 479 & 682 \\
Hortalizas y plantas & 84 & 105 & 79 \\
Frutales & 54 & 88 & 46 \\
\hline Total & 1684 & 732 & 8059 \\
\hline
\end{tabular}

FUENTE: Ministerio de Medio Ambiente y Medio Rural y Marino

De los anteriores datos censales no se puede concluir que se haya dado una diversificación de la producción agrícola, al contrario la tendencia, al menos en los municipios de la vertiente atlántica, se encamina hacia un terrazgo cada vez más reducido, fragmentado, disperso y orientado hacia la producción forrajera y hortícola. Lo que sí se advierte es una creciente especialización ganadera en ambas vertientes, atlántica y mediterránea. En la primera, esta especialización cuenta ya con una arraigada tradición al cimentarse de forma paralela al proceso de industrialización que arranca en la segunda mitad del siglo XIX, y se manifiesta por la progresiva invasión del antiguo terrazgo agrícola por parte del praderío que, junto con el bosque de coníferas, constituyen los dos principales componentes de su paisaje agrario. En la vertiente mediterránea la especialización es más reciente y fruto de la reestructuración agraria iniciada a partir de mediados del siglo pasado. Los datos censales de 1989 y 1999 reflejan un incremento del número total de Unidades Ganaderas (U.G.) en las tres zonas de estudio a pesar del descenso del número de explotaciones. El mayor, del 51\%, se registra en la Montaña Alavesa gracias al aumento de la cabaña en todos sus municipios; el del Macizo del Gorbea, del 31\%, se debe fundamentalmente al incremento de la ganadería en los municipios alaveses de Zuia y Zigoitia; en el Macizo de Ernio tan sólo lo ha sido del 10\%. La vocación ganadera de estas zonas se concentra en la cría del bovino y del ovino. La cabaña principal y la que más ha crecido es la bovina, la cual representaba en el año 1999 el 78,7\% de las U.G. en el Macizo del Ernio, el 71\% en la zona del Gorbea y el 58,8\% en la Montaña Alavesa; al mismo tiempo se ha producido un cambio en muchas explotaciones que han abandonado su orientación productiva láctea por la cárnica, lo que ha condicionado una transformación de las razas y una gestión más extensiva de la explotación con un mayor aprovechamiento a diente de los prados y de los pastos. La ovina y caprina ha perdido peso relativo en el Macizo del Gorbea, donde representa el 17,6\% de las U.G., y se ha incrementado en la Montaña Alavesa (22,5\% del total de las U.G.) y Macizo del Ernio (15,9\%). 
Mejores resultados han tenido las iniciativas de fomento de la producción de calidad. En 1989 la administración vasca crea el Label Vasco de Calidad Alimentaria (decreto 203/89) con un doble objetivo: por un lado, proporcionar a los consumidores un medio de reconocer los productos de calidad superior a la media general del conjunto de la oferta alimentaria y, por otro, que los productores y elaboradores de productos agroalimentarios de calidad dispongan de distintivos que les permita destacarse del anonimato (GALDÓs, 2004). Hasta el año 2008, según se recoge en el informe de la Fundación Kalitatea, organismo encargado de promover y desarrollar la calidad alimentaria, son 13 los productos amparados bajo la marca de Eusko Label y 2.400 los productores acogidos a ella en el País Vasco. De todos los productos, el más destacado en número de productores y volumen comercializado es la carne de vacuno "Euskal Okela", reconocida también como Indicación Geográfica Protegida en el marco de la normativa europea. En las zonas de estudio, de creciente especialización ganadera tal como se ha comentado, también es este producto con label el más importante cuando no el único. Así, en el Macizo del Gorbea y en la Montaña Alavesa sólo hay productores de Euskal Okela mientras que en el Macizo del Ernio existen algunas otras explotaciones dedicadas a la producción hortícola de calidad. Algunos ganaderos de ovino han optado por la fabricación artesanal de quesos de Denominación de Origen Idiazabal, producido a partir de la leche de ovejas de raza latxa. Sin embargo, son todavía pocos los agricultores y ganaderos dispuestos a mejorar los procesos productivos y cumplir los requisitos que exige una producción de calidad que, en general, tiene la ventaja de obtener precios más altos en el mercado contribuyendo a incrementar sus rentas agrarias; además en los últimos años ha disminuido el número de productores acogidos a la marca Eusko Label.

Cuadro 4. Productores acogidos a distintivos de calidad, 2008

\begin{tabular}{lrrr}
\hline \multicolumn{1}{c}{ Productores } & Macizo Gorbea & Macizo Ernio & Montaña Alavesa \\
\hline Eukal Okela* & 48 & 81 & 13 \\
Tomate del País Vasco & -- & 1 & - \\
Euskal baserri & -- & 5 & - \\
Queso Idiazabal & 5 & 5 & 1 \\
\hline
\end{tabular}

*Carne de vacuno; **Producto hortofrutícola

FUENTE: Fundación Kalitatea y Consejo Regulador D.O. Idiazabal

Por último, en lo que respecta a la explotación forestal, se comprueba un proceso diferente en las zonas de estudio. Como indicador del grado de sostenibilidad de la gestión forestal se ha utilizado la evolución de la relación entre especies forestales autóctonas y cultivos forestales. De acuerdo con los datos de los Inventarios Forestales de 1996 y 2005, el único caso en el que se aprecia un proceso favorable en el sentido en que las especies autóctonas ganan terreno a las especies de cultivo es en el macizo de Gorbea, mientras que en el de Ernio el 
proceso es inverso. En la Montaña Alavesa no se registra una tendencia clara en ningún sentido ya que ambas tipos de especies pierden extensión durante este período.

\section{INICIATIVAS PARA EL DESARROLLO INDUSTRIAL}

Ante la pérdida de importancia del sector agrario como motor de la economía, uno de los objetivos del desarrollo rural pasa a ser la diversificación funcional y económica del mundo rural y la promoción de estrategias y medidas destinadas a todos los habitantes y no únicamente a los agricultores. En esa aspiración se fundamenta el Eje 3 del Programa de Desarrollo Sostenible del Medio Rural de España 2007-2013 y del Programa de Desarrollo Rural Vasco 2007-2013, los cuales se concretan y aplican a través de los distintos Programas de Desarrollo Rural de carácter comarcal. Entre las medidas que articulan ese eje sobresale el fomento de actividades no agrícolas y, en este contexto, las ayudas destinadas a la creación y al desarrollo de microempresas, a la atracción de industrias al medio rural y al fomento de actividades turísticas.

Resulta conocido que, a menudo, los procesos de industrialización han evadido las zonas de montaña, en razón de sus menores ventajas de situación frente a otros ámbitos geográficos, de sus limitaciones para proporcionar mano de obra y población consumidora suficiente y, sobre todo, de su peor accesibilidad. Ahora bien, procede insistir -una vez más- en la diversidad interna que encierra esa realidad territorial y, por consiguiente, en la necesidad de matizar dicha afirmación. Al igual que en el conjunto del medio rural, la tipología industrial de los territorios montañosos suele ser variada: en unos casos, responde a procesos de industrialización endógena, y por ello, autóctona, basada en los recursos locales y en la capacidad de la población dando lugar a modelos de desarrollo local; en otros, se halla activada desde el medio urbano y se hace patente en la implantación de empresas exógenas, de procedencia regional, nacional o incluso internacional. A ellos se suman los procesos de difusión de innovación y de renovación de tradicionales empresas de carácter artesanal.

Si tenemos en cuenta, por un lado, que la actividad industrial puede considerarse por su permanencia y trascendencia como un rasgo regional definitorio del País Vasco (RUIZ URRESTARAZU y GALDÓs, 2008, 70) y, por otro lado, que la montaña vasca se extiende por más de las tres quintas partes de toda la región cabe esperar que en ella la impronta industrial sea mayor que la existente en otros territorios montañosos de España. Así es, en efecto, pero, como ya ha sido comentado, la heterogeneidad de la montaña vasca constituye la nota distintiva atendiendo a muchos aspectos, entre ellos, al peso que alcanza el sector industrial en la economía y en el empleo. Aunque ninguno de los casos de estudio seleccionados forma parte de lo que se ha dado en llamar "montaña industrializa- 
da" -lo cual abriría todavía más el abanico de matices- no obsta para que se aprecien comportamientos diferenciados a ese respecto en la montaña atlántica y en la subatlántica y submediterránea. Eso sí, los tres espacios montañosos comparten una situación de partida de baja densidad industrial -expresada tanto en número de empresas como de empleos por $\mathrm{Km}^{2}$ - que se hace particularmente notoria en el caso de la Montaña Alavesa y del Macizo del Gorbea, y adquiere menor intensidad en el Macizo de Ernio (en buena medida, gracias a su pequeña extensión superficial).

Pero según el Catálogo Industrial de 1994 y del correspondiente al año 2009, se advierte que se ha registrado un aumento del número de empresas industriales en las tres zonas durante ese periodo de tiempo, el cual ha sido más acusado en el macizo del Gorbea (al pasar de 5 a 32 industrias) que en el Macizo de Ernio (8 y 29) y en la Montaña Alavesa (5 y 7). Dicho incremento se ha visto acompañado de un ascenso del número de empleos industriales en todos ellos (equivalente a un $37,5 \%$ y a una ganancia global de 2.200 trabajos), si bien, en este caso, se ha dado en mayor grado en el Macizo del Ernio que en el del Gorbea. La instalación de nuevas industrias en estos últimos años se ha producido en la gran mayoría de los municipios de montaña estudiados pero, particularmente, en Zuia, Artea, Dima y Orozko (Macizo del Gorbea), en Asteasu (Macizo de Ernio), y en Bernedo y Arraia-Maeztu (Montaña Alavesa). En el otro extremo, se sitúan los municipios vizcaínos de Ubide y Zeanuri, en el área del Macizo del Gorbea, de Alkiza, Beizama, Hernialde y Larraul, en la del Ernio, y de Lagrán y Peñacerrada, en la Montaña Alavesa que -según la fuente citadasiguen sin acoger empresa alguna. Al hilo de ello, conviene recordar la dificultad que encuentran los municipios más pequeños, con unos ingresos generalmente reducidos, para crear nuevos espacios productivos y atraer inversiones y nuevas actividades económicas.

Esa tendencia alcista se confirma también a través de la evolución experimentada por el número de establecimientos de industria y energía en los años 1996, 2001 y 2008, representada en la figura 5. Se aprecia que, según este indicador, el incremento ha alcanzado el 50\% en el Macizo del Ernio, casi el 33\% en el Macizo de Gorbea (por el considerable aumento registrado en Artea y, en menor medida, en Zigoitia) y el $8 \%$ en la Montaña Alavesa (sobre todo, en Bernedo). Como resultado de ello, los municipios que en todos esos años han albergado un mayor volumen de establecimientos son los más grandes de los respectivos ámbitos, esto es, Asteasu, Orozko y Campezo/Kanpezu (31, 19 y 12, respectivamente, en 1996 y 48, 23 y 11 en el 2008). Para entender las discrepancias respecto a lo señalado anteriormente conviene recordar dos cuestiones: por un lado, la diferencia semántica de las palabras "empresa" y "establecimiento", en tanto en cuanto aquélla puede integrar uno o varios de éstos; y, por otro lado, 
la limitación inherente al Catálogo Industrial del País Vasco en donde, a menudo, no aparecen registradas las empresas de menos de 5 o 10 trabajadores.

Figura 5. Evolución del número de establecimientos de industria y energía.

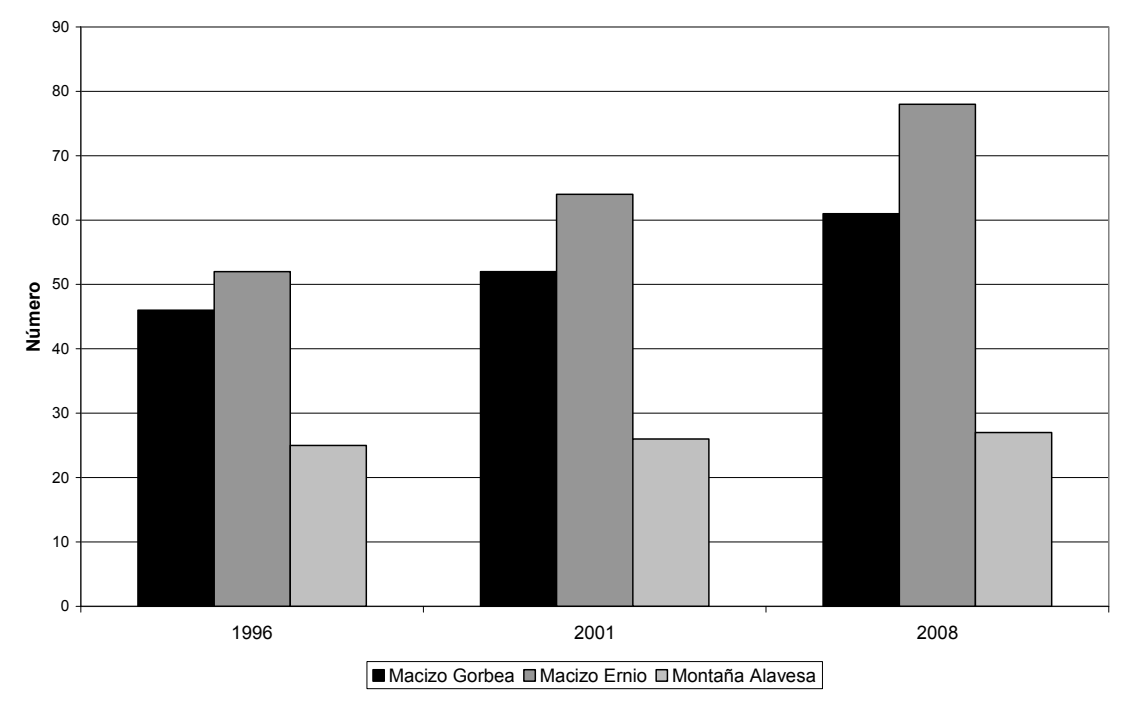

FUENTE: EUSTAT.

Sin lugar a dudas, el tipo de industria predominante es la pequeña empresa: 56 de las 68 existentes en la totalidad del ámbito estudiado, esto es el 82,35\%, posee menos de 50 empleados; 5 , o lo que es lo mismo el 7,35\%, entre 51 y 100 ; y 7 (el 10,2\%) entre 101 y 250 , no habiendo ninguna que supere este último umbral. A grandes rasgos, estas proporciones medias se mantienen en cada una de las áreas de estudio; no obstante, en el Macizo de Ernio se observa que el protagonismo de las empresas de menor tamaño disminuye ligeramente a favor de los dos siguientes intervalos de empleo. Así pues, se pone de manifiesto el claro protagonismo de la pequeña empresa en estos entornos montañosos, la presencia -aunque en menor cuantía- de empresas medias y la total ausencia de grandes factorías con más de 250 empleados. Si en el mismo cuadro 5 observamos la distribución de los empleos según el tamaño de las empresas, se aprecia -como cabía esperar- que no se da un reparto tan sesgado hacia los valores más bajos sino una mayor participación de los estratos superiores. De este modo, aunque únicamente son 7 las empresas que poseen entre 101 y 250 empleados aglutinan al $45 \%$ del total de trabajadores industriales, una proporción ligeramente superior a la alcanzada por las 56 empresas más pequeñas que, en conjunto, reúnen al 42,24\% de ellos. Resulta significativo comprobar que, según el Catálogo Industrial, en la Montaña Alavesa una única empresa con 110 empleados es capaz de agrupar a más del $57 \%$ del empleo total generado por el 
sector industrial en esa comarca. Por lo que se refiere al tamaño medio de los establecimientos industriales -expresado en número de empleos por establecimiento- hay que decir que los valores más elevados se concentran en Zigoitia, Asteasu, Orozko y Zuia (con 34,11, 18,9, 16,48 y 14,14 respectivamente).

A la luz de lo expuesto, no puede afirmarse que se haya producido -como ha sucedido en el sector agrario- un significativo proceso de concentración empresarial, esto es, una disminución del número de empresas y establecimientos industriales y un considerable aumento de su tamaño medio sino un incremento de los mismos y un mantenimiento de sus rasgos estructurales atendiendo al tamaño, establecido en función del número de empleos. Por consiguiente, siguen predominando las empresas pequeñas, con un número de empleados reducido y unos niveles de facturación igualmente discretos que, en muchos casos, corresponden a negocios familiares que dan trabajo a 2 o 3 personas.

Cuadro 5. Estructura empresarial por tamaños de empleo

\begin{tabular}{|c|c|c|c|c|c|c|}
\hline & \multicolumn{2}{|c|}{ Macizo del Gorbea } & \multicolumn{2}{|c|}{ Macizo del Ernio } & \multicolumn{2}{|c|}{ Montaña Alavesa } \\
\hline \multicolumn{7}{|c|}{ Empresas } \\
\hline$N^{o}$ empleos & $N^{o}$ & $\%$ & $N^{o}$ & $\%$ & $N^{o}$ & $\%$ \\
\hline$<=50$ & 27 & 84,38 & 23 & 79,31 & 6 & 85,71 \\
\hline $51-100$ & 2 & 6,25 & 3 & 10,34 & & 0,00 \\
\hline $101-250$ & 3 & 9,38 & 3 & 10,34 & 1 & 14,29 \\
\hline $251-500$ & & & & & & \\
\hline$>=501$ & & & & & & \\
\hline TOTAL & 32 & 100,00 & 29 & 100,00 & 7 & 100,00 \\
\hline \multicolumn{7}{|c|}{ Empleo } \\
\hline$N^{o}$ empleos & $N^{o}$ & $\%$ & $N^{o}$ & $\%$ & $N^{o}$ & $\%$ \\
\hline$<=50$ & 511 & 42,02 & 500 & 42,48 & 80 & 42,11 \\
\hline $51-100$ & 130 & 10,69 & 192 & 16,31 & & 0,00 \\
\hline $101-250$ & 575 & 47,29 & 485 & 41,21 & 110 & 57,89 \\
\hline $251-500$ & & & & & & \\
\hline$>=501$ & & & & & & \\
\hline TOTAL & 1216 & 100,00 & 1177 & 100,00 & 190 & 100,00 \\
\hline
\end{tabular}

FUENTE: Catálogo Industrial y de Exportadores del País Vasco 2009, Gobierno Vasco.

Resulta conocido que, tradicionalmente, los sectores de la alimentación, textil y confección, madera y fabricación de muebles, ligados a los recursos territoriales, han sido los más representativos de las zonas rurales más profundas, mientras que en aquellas mejor comunicadas o de carácter periurbano ha predominado la diversidad. No puede hablarse de una especialización definida en lo que se refiere a la orientación productiva de las industrias instaladas en las zonas montañosas vascas, lo cual no es óbice para señalar ciertas tendencias. 
En la montaña guipuzcoana estudiada, al igual que en el conjunto del País Vasco, los productos metálicos y la fabricación de maquinaria constituyen las ramas más destacadas: a ellas se dedican 18 empresas, es decir, algo más de las tres quintas partes del total, y unos 790 empleos, que suponen el 65,4\%. Les siguen las centradas en la fabricación de papel, pasta de papel y derivados ( 2 empresas y 101 empleos que representan el $6,9 \%$ y el $8,4 \%$ respectivamente). Verdaderamente hay que reconocer que no se trata de vocaciones nuevas sino que estas orientaciones ya existían en 1994 y se hallan en concordancia con las que tradicionalmente han prevalecido en la cuenca del Oria (sobre todo, en Tolosa) y en Urola Costa (particularmente, en Azkoitia y Azpeitia). Por su parte, en el Macizo del Gorbea se observa que la dedicación productiva se asienta equitativamente en los productos alimenticios y bebidas, por un lado, y en los artículos metálicos, por el otro (con 6 empresas y un porcentaje del 18,7\%, en ambos casos, y un volumen de empleo de 625 y 193 respectivamente). Le siguen en importancia los trabajos de construcción (4 empresas, que suponen el 12,5\% de todas las existentes, y 76 empleos equivalentes al 5,3\%). Finalmente en la Montaña Alavesa se aprecia cierta supremacía de las dedicadas a la madera y fabricación de papel, pasta de papel y derivados (3 empresas, esto es, el 42,7\% y 150 empleos).

Como se ha avanzado, las factorías más grandes ubicadas en las tres zonas de montaña suman siete y todas ellas cuentan con más de 100 trabajadores, reuniendo en total cerca de 1.200 empleos. Estas mayores empresas pertenecen al sector alimenticio y de bebidas, al de maquinaria y productos metálicos, al de la madera y corcho, y a servicios de investigación y desarrollo. Su localización coincide con los principales asentamientos de población y municipios fabriles de cada una de las tres áreas montañosas: Orozko, en la vertiente septentrional del Macizo del Gorbea, Zigoitia, en la meridional del mismo, Asteasu y Errezil, en el Macizo del Ernio, y Campezo en la Montaña Alavesa. Resulta digna de mención la instalación de dos grandes plantas galleteras en el primero de ellos, comercializadas con el nombre de ARTIACH, y también de una empresa embotelladora de bebidas en el segundo (Compañía de bebidas Pepsico, S.A.), una empresa multiplanta que se halla asimismo instalada en Vizcaya (Arrigoriaga) y en Guipúzcoa (Usurbil). Por su parte, en el Macizo del Ernio dos de sus tres mayores empresas pertenecen al sector de la maquinaria y productos metálicos: ECHESA, S.A., dedicada a la fabricación de engranajes y otros elementos de transmisión, así como de reductores, multiplicadores y variadores de velocidad, y DOMUSA CALEFACCIÓN S. COOP, a la fabricación de calderas de calefacción. La tercera, GAMESA ENERGY TRANSMISION, S.A., se adscribe al sector de las energías renovables y persigue la prestación de servicios empresariales vinculados a la investigación y al desarrollo. Si bien su centro de administración se encuentra en el Parque Tecnológico vizcaíno de Zamudio, en el municipio gui- 
puzcoano de Asteasu cuenta con una planta dedicada a la fabricación de componentes para multiplicadoras y reductores de velocidad en aerogeneradores, en la cual trabajan 157 personas. A su vez, el mayor establecimiento industrial de la Montaña Alavesa pertenece al sector de la madera (MADERAS GAMIZ, S.A.) y proporciona 110 empleos. Sólo tres de estas grandes empresas existían en 1994, y de ellas dos proporcionaban en ese momento menos de 100 empleos, lo cual refleja una evolución favorable para nuestras áreas de estudio.

Según la Encuesta Industrial Anual de Empresas (INE, 2007) la industria agroalimentaria española es el subsector industrial más importante en el medio rural. La relevancia que dicho sector alcanza en las tres zonas queda enmascarada por las limitaciones de la fuente utilizada (Catálogo Industrial del País Vasco), ya que buena parte de ellas no sobrepasan los 5 empleos y, a menudo, quedan obviadas en la misma. Así según la información complementaria obtenida gracias a Nekanet (portal de referencia del sector agroalimentario vasco y del espacio rural y pesquero en Internet) existen 13 en la Montaña Alavesa, otras 13 en el Macizo del Gorbea y 7 en el del Ernio. Desde el punto de vista estructural se caracterizan por su excesiva atomización. Cuantitativamente sobresalen las relacionadas con la miel en la Montaña Alavesa y las queserías en el Macizo del Ernio, mientras que en el del Gorbea la distribución entre las distintas ramas del sector agroalimenticio resulta más heterogénea (industrias cárnicas, de alimentación animal y galleteras, en la vertiente septentrional, e industrias cárnicas, queserías, bebidas, etc., en la meridional). Como es habitual, mantienen una estrecha vinculación con las materias primas de las respectivas zonas, transformándolas y creando nuevos productos de mayor valor añadido.

La atracción de empresas industriales a estos conjuntos montañosos se halla inducida, en alto grado, por la oferta de suelo industrial y por la promoción de su ocupación mediante políticas públicas. Así, atendiendo a las cifras, entre 1998 y el año 2008 se ha producido un incremento del suelo calificado para actividades económicas del $34 \%$ que obedece a la expansión producida al respecto en el Macizo del Gorbea y en la Montaña Alavesa, ya que en el Macizo del Ernio no se han registrado cambios en este sentido. A tenor de todo ello, en el año 2008 la superficie de suelo calificado para actividades económicas ocupa en el conjunto de los tres espacios montañosos $234,53 \mathrm{Ha}$. Como es sabido, dicha calificación comprende no sólo el suelo dedicado o previsto para actividades industriales sino también para actividades terciarias, servicios empresariales, áreas comerciales de grandes extensiones y nuevas actividades económicas. Desde el punto de vista espacial esa extensión se reparte de forma muy desigual entre el Macizo del Gorbea (que reúne el 51\%), la Montaña Alavesa (el 33,8\%) y el Macizo del Ernio (el 15,2\%), siendo asimismo desequilibrada la distribución interna en el seno de estos territorios. Los municipios alaveses de Zigoitia 
y Campezo y el guipuzcoano de Asteasu ocupan las primeras posiciones a este respecto, de suerte que contabilizan las mayores superficies brutas ocupadas y destinadas a actividades económicas.

Buena parte de ese desarrollo positivo responde a las medidas de promoción industrial, vinculadas al desarrollo local, emprendidas por las diferentes Administraciones. Entre las principales intervenciones llevadas a cabo en los municipios de las zonas de montaña estudiadas destacan la creación de un industrialdeak en Campezo (Montaña Alavesa) así como de un polígono industrial en Artea (Macizo del Gorbea). El primero, promovido por la sociedad semipública SPRI (Sociedad de Promoción y Reconversión Industrial), la Diputación Foral de Alava y el propio Ayuntamiento de Campezo, cuenta con una superficie bruta de 1 ha. y se sitúa en un entorno netamente agrícola, junto al principal eje de comunicación de la comarca, esto es, la carretera A-132. En concordancia con los objetivos de los industrialdeak, que pretenden potenciar las empresas de nueva creación, de tamaño pequeño y medio, y de carácter innovador, alberga ocho factorías de orientación productiva variada. Por su parte, el segundo, corresponde al Polígono industrial Bildosola Auzunea y abarca 27 Ha distribuidas entre el municipio de Artea y su vecino Arantzazu (no incluido en los casos de estudio). Fue auspiciado por la SPRI y los Ayuntamientos respectivos e inaugurado en el año 2006 con la previsión de instalar 41 empresas y reunir a 950 trabajadores. A ellos se suman otras iniciativas como la habilitación de suelo industrial en Bernedo, Arraia-Maeztu y Valle de Arana (Primer Programa Operativo de Desarrollo Rural de la Montaña Alavesa 1991-1993).

\section{INICIATIVAS DE TERCIARIZACIÓN Y PROMOCIÓN DEL TURISMO}

La transformación de las economías de actividades de producción en actividades de servicios, también conocida como terciarización, es una tendencia característica de las sociedades desarrolladas de las últimas décadas que no sólo afecta al mundo urbano sino también al medio rural y, dentro de éste, a las áreas de montaña. Este proceso de reconversión productiva y renovación funcional se halla estrechamente imbricado con las políticas y estrategias de desarrollo que, tal y como se ha estado analizando, inducen a la diversificación económica. En este contexto, el turismo, como actividad inherente al proceso de terciarización de la economía, a diferentes escalas espaciales y en distintos entornos, está siendo un factor decisivo para la reorganización y configuración de muchas montañas europeas. Vamos a intentar definir el alcance de este proceso en los casos de estudio vascos, a través de algunos indicadores.

La importancia del sector terciario en los territorios montañosos del País Vasco puede comprobarse desde la doble perspectiva del empleo y de su participa- 
ción en la economía. Atendiendo al primer aspecto, el mayor protagonismo se produce en el Macizo del Gorbea donde, según la Tesorería General de la Seguridad Social, en el año 2007 los trabajadores en los servicios sumaban 2.216 y representaban cerca del $62 \%$ del total (frente al $7,5 \%$ correspondiente al sector agrario y el $30,8 \%$ a la industria y a la construcción). Ello, en buena medida, obedece al elevado peso que posee en los municipios alaveses de esa área $(85,7 \%$ en Zigoitia y $70,5 \%$ en Zuia). Por su parte, tanto en el Macizo del Ernio como en la Montaña Alavesa la participación relativa de los trabajadores en el sector terciario es significativamente más reducida $(26,43 \%$ y $22,25 \%$ respectivamente, equivalentes a 508 y 229 empleos), en beneficio de la industria y la construcción que, juntas, acaparan el $64 \%$ y el $49 \%$ en dichos territorios. Esto confirma, una vez más, la importancia que poseen las actividades industriales en el tejido productivo de las montañas guipuzcoanas y, a su vez, el significativo papel que todavía desempeñan los trabajadores del sector agrario en la Montaña Alavesa (28,7\%, un porcentaje que supera en más de seis puntos el correspondiente a los servicios). Por lo que se refiere a su aportación a la economía se advierte que ésta también adquiere mayores proporciones en el Macizo del Gorbea que en los otros dos ámbitos montañosos; resulta particularmente destacado el protagonismo económico del sector terciario en los municipios de Bernedo (Montaña Alavesa), Zuia y Zeanuri (Macizo del Gorbea), en la medida en que llega a rebasar el $60 \%$ del valor añadido bruto de la economía municipal (un porcentaje que constituye la media regional). Asimismo se aprecia que dicha contribución ha aumentado, entre los años 1996 y 2005, en 13 de los 22 municipios que componen los tres casos de estudio, es decir en las tres quintas partes de ellos.

Cuadro 6. Distribución de trabajadores por sectores económicos

\begin{tabular}{lrrrrrrrrr}
\hline & \multicolumn{3}{c}{$A$} & \multicolumn{2}{c}{$B$} & \multicolumn{2}{c}{$D$} & \multicolumn{1}{c}{$E$} \\
\cline { 2 - 10 } & $N^{o}$ & $\%$ & $N^{o}$ & $\%$ & $N^{o}$ & $\%$ & $N^{o}$ & $\%$ & $N^{o}$ \\
\hline Macizo Gorbea & 268 & 7,46 & 702 & 19,54 & 406 & 11,30 & 2216 & 61,69 & 3592 \\
Macizo Ernio & 183 & 9,52 & 1055 & 54,89 & 176 & 9,16 & 508 & 26,43 & 1922 \\
Montaña Alavesa & 296 & 28,77 & 370 & 35,96 & 134 & 13,02 & 229 & 22,25 & 1029 \\
\hline Casos de estudio & 747 & 11,42 & 2127 & 32,50 & 716 & 10,94 & 2953 & 45,13 & 6543 \\
\hline
\end{tabular}

$A$, Trabajadores en el sector agrario; $B$, Trabajadores en la industria; $C$, Trabajadores en la construcción; D, Trabajadores en los servicios; E. Total trabajadores FuENTE: Tesorería General de la Seguridad Social, 2007. Caja España.

Como es bien sabido, la promoción del turismo como estrategia de desarrollo rural ha sido incitada durante las dos últimas décadas desde numerosos programas y planes de carácter europeo, nacional, regional y local (LEADER, Programa de Desarrollo Rural Sostenible de España, Plan de Desarrollo Rural Vasco, Programas de Desarrollo Rural Comarcales, etc.). El turismo se concibe como 
un eficaz instrumento de revitalización de zonas rurales desfavorecidas capaz, entre otras cosas, de generar rentas y empleos, máxime teniendo en cuenta los siguientes factores: la oportunidad que ofrece la creciente revalorización del campo y de la montaña por parte de una demanda esencialmente urbana, que dispone de un tiempo de ocio cada vez más fragmentado y a la que no le satisface el turismo masivo, y las grandes potencialidades recreativas que presentan buena parte de esas zonas rurales en razón de la riqueza del patrimonio natural y cultural que habitualmente albergan (PORCAL, 2003, 66). No hay que olvidar tampoco que el sector turístico -aunque con oscilaciones- ha mantenido una tendencia ascendente en los últimos años hasta representar actualmente el 5,2\% del P.I.B. del País Vasco y el 4,9\% del empleo, unas proporciones todavía modestas pero con capacidad de crecimiento. En unos y otros planes y programas de desarrollo rural y de desarrollo turístico se propone crear una oferta estructurada e integral para el uso recreativo que aúne recursos, infraestructuras y servicios y que, en definitiva, permita la consolidación de productos turísticos, susceptibles de promoción y comercialización. En el marco de los productos turísticos incluidos en el I Plan de Marketing del Turismo Vasco, Hor Dago! Plana, 2009-2012 y, más concretamente, de los que en nuestros días se están ofertando en el mercado nacional e internacional, los tres territorios de montaña objeto de estudio participan de uno de los productos "estrella" de la región: el paisaje natural de Euskadi, difundido con la marca Berdea. Paisajes, cultura y tradiciones rurales, gastronomía tradicional y productos autóctonos de calidad (Eusko Label), parques naturales, actividades en la naturaleza (BTT, senderismo, orientación, espeleología, etc.) y alojamientos rurales son algunos de los elementos que articulan ese producto turístico. Junto a él la Montaña Alavesa y el Macizo del Gorbea acogen también productos turísticos más específicos y, usualmente, de carácter complementario tales como el turismo de golf.

Para llevar a cabo ese proceso de transformación de recursos en productos turísticos el Gobierno Vasco ha articulado ayudas económicas que han propiciado la creación de dos tipos de planes: por un lado planes de dinamización turística de carácter territorial o planes turísticos comarcales y, por otro lado, planes municipales de dinamización turística o iniciativas de creación de productos turísticos. En este sentido, se ha realizado un Plan de Dinamización Turística de la Montaña Alavesa por parte de la Asociación de Desarrollo Rural Izki Landa. Uno de los principales objetivos que persigue es la consolidación del producto turístico de naturaleza, una finalidad que, a su vez, se halla claramente explicitada en el Plan de Competitividad del Turismo Vasco 2005-2009 para el conjunto del País Vasco, en virtud de sus buenas perspectivas de crecimiento.

La riqueza del patrimonio natural de los tres espacios montañosos estudiados se traduce en la existencia de sendos espacios naturales protegidos: el Parque 
Natural del Gorbea, el de Izki y el espacio integrado en la Red Natura 2000 Ernio-Gatzume. El primero, fue declarado como tal en 1994 (Decreto 228/94, de 21 de Junio) y, con sus algo más de 20.000 Ha., es el más grande del País Vasco: en él participan Areatza, Artea, Orozko, Zeanuri y Zeberio, en la vertiente septentrional, y Urkabustaiz, Zigoitia y Zuia, en la meridional. El segundo, aprobado en 1998 (Decreto 64/98, de 31 de Marzo), consta de unas 9.000 Ha. distribuidas entre los municipios de Arraia-Maeztu, Bernedo y Campezo/Kanpezu. El tercero, declarado Lugar de Importancia Comunitaria, abarca $2.158 \mathrm{Ha}$., de las cuales 1.994 pertenecen a los municipios guipuzcoanos estudiados. Analizando los Planes Rectores de Uso y Gestión de los Parques Naturales se advierte que ambos contemplan entre sus objetivos el fomento del turismo y de las actividades recreativas y la potenciación social y económica del área de influencia.

El impulso del turismo de naturaleza, en muchos casos, se ha articulado mediante el apoyo otorgado al ecoturismo, al senderismo, a las bicicletas de montaña y a la hípica. En este sentido caben ser señaladas algunas iniciativas puestas en marcha en esos territorios ${ }^{2}$ : la promoción y difusión de la red de senderos balizados existentes (en particular, el GR 123, en el Macizo del Gorbea, el GR 38, en la Montaña Alavesa y los GR 9, 21 y 35, en el del Ernio, a los que se suma un amplio espectro de rutas PR y SL); la inauguración de un centro BTT en la Montaña Alavesa, que oferta una malla de rutas y de circuitos pensados para la práctica de la bicicleta todo terreno; y la creación de una serie de centros hípicos (Centro Ecuestre y C.H. Deportivo Aguarke en Antoñana, Montaña Alavesa; Hípica Eribe e Hípica Zelara, en Zigoitia, Macizo del Gorbea).

A continuación, vamos a tratar de averiguar hasta qué punto se está llevando a cabo esa consolidación del producto a través de la evolución experimentada por los alojamientos turísticos y por los establecimientos de hostelería en su conjunto. Recuérdese que desde 1998 el agroturismo ha sido la modalidad particularmente apoyada desde la administración pública vasca, en tanto en cuanto se concibe como una actividad complementaria a la renta agraria y como una vía de afianzar la sostenibilidad de las explotaciones (Porcal, 2002, 459), de suerte que se ha incluido también como medida de diversificación hacia actividades no agrícolas en el Plan de Desarrollo Rural Sostenible de la C.A.P.V. 2007-2013.

\footnotetext{
${ }^{2}$ Las principales iniciativas ligadas al desarrollo del turismo rural y ecoturismo en la Montaña Alavesa así como su vinculación con los programas de desarrollo rural emprendidos fueron abordados en el artículo: Porcal Gonzalo, M.C. y Armentia Pinedo, F. (2002) «Algunas iniciativas significativas encaminadas al desarrollo del turismo rural y del ecoturismo en una comarca desfavorecida del País Vasco: la Montaña Alavesa», Lurralde, nº 24, pp. 21-44.
} 
Cuadro 7. Evolución de la oferta de alojamientos turísticos

\begin{tabular}{|c|c|c|c|c|c|}
\hline & \multicolumn{5}{|c|}{ Establecimientos } \\
\hline & \multicolumn{2}{|c|}{1995} & \multicolumn{2}{|c|}{2005} & $1995=100$ \\
\hline & $N^{o}$ & $\%$ & $N^{o}$ & $\%$ & $N^{o}$ \\
\hline Montaña Alavesa & 12 & 63.16 & 27 & 52.94 & 225.00 \\
\hline Macizo Gorbea & 6 & 31.58 & 16 & 31.37 & 266.67 \\
\hline Macizo Ernio & 1 & 5.26 & 8 & 15.69 & 800.00 \\
\hline \multirow[t]{4}{*}{ Casos de estudio } & 19 & 100.00 & 51 & 100.00 & 268.42 \\
\hline & \multicolumn{5}{|c|}{ Plazas } \\
\hline & \multicolumn{2}{|c|}{1995} & \multicolumn{2}{|l|}{2005} & $1995=100$ \\
\hline & $N^{o}$ & $\%$ & $N^{o}$ & $\%$ & $N^{o}$ \\
\hline Montaña Alavesa & 176 & 65.43 & 357 & 57.77 & 202.84 \\
\hline Macizo Gorbea & 81 & 30.11 & 177 & 28.64 & 218.52 \\
\hline Macizo Ernio & 12 & 4.46 & 84 & 13.59 & 700.00 \\
\hline Casos de estudio & 269 & 100.00 & 618 & 100.00 & 229.74 \\
\hline
\end{tabular}

FUENTE: Registro de Alojamientos Turísticos, Gobierno Vasco.

Aunque partiendo de unos valores absolutos muy modestos, la oferta de alojamientos turísticos no ha dejado de progresar desde 1995 hasta el año 2005 en el conjunto de los tres territorios de montaña analizados (pasándose de 19 a 51 establecimientos y de 269 a 618 plazas). En la actualidad, disponen de 135 plazas de alojamiento en agroturismos, 212 en casas rurales, 249 en hoteles y pensiones y 22 en apartamentos. El mayor auge experimentado durante el decenio analizado lo han protagonizado las casas rurales (26 plazas en 1995 y 212 en el 2005), seguidos de los hoteles-pensiones (156 plazas en 1995 y 249 plazas) y, por último, de los agroturismos (87 y 135 plazas). Por lo que atañe a su distribución espacial, tanto en 1995 como en el 2005, se confirma una mayor oferta de establecimientos y plazas en la Montaña Alavesa que en los otros dos territorios montañosos. En todo caso, se advierte que, en términos relativos, su peso ha disminuido en ese periodo de tiempo, siendo el Macizo de Ernio el que ha mostrado un comportamiento más dinámico.

También la evolución del conjunto de establecimientos de hostelería muestra una tendencia positiva de en torno al 36\%, con 134 establecimientos registrados en 1995 y 182 en el 2008. En términos relativos el incremento más acusado se ha dado en la Montaña Alavesa (particularmente en los municipios de Peñacerrada, y Bernedo) y en el macizo del Gorbea, gracias, sobre todo, a Zigoitia.

Por lo que se refiere al turismo de golf, éste se estructura en estas tres áreas de montaña en torno a cuatro campos situados en Dima, Zuia, Bernedo y Lagrán. Estos dos últimos corresponden al Complejo Izki Golf y su principal singularidad radica en que -una vez declarada en 1989 la comarca como Zona Objetivo 
5b - surgió al amparo de un Plan de Desarrollo Rural, con un carácter social (PORCAL, 2003, 75).

Pero, además de la promoción del turismo y de la mejora de la oferta de alojamiento en este sentido, las iniciativas de terciarización se hacen patentes en la ampliación de la infraestructura comercial que, entre 1995 y el 2008, se ha producido con mayor intensidad en el área del Macizo del Gorbea que en la del Ernio, al suponer, en el primer caso, un incremento del número de establecimientos comerciales y de reparaciones de vehículos de motor del $85 \%$ y, en el segundo, del 67\%. Por su parte, en la Montaña Alavesa los datos apuntan a una contracción del $18 \%$. Como resultado de todo ello, en la actualidad el Macizo del Gorbea concentra 191 licencias comerciales, 72 el del Ernio y 55 la Montaña Alavesa. Resulta digna de mención la apertura en el año 2001 de un gran centro comercial en el municipio de Zigoitia, el Parque Comercial Gorbea, que cuenta con una superficie total construida de $75.000 \mathrm{~m}^{2}$, de los cuales $56.000 \mathrm{se}$ destinan a actividades comerciales y de ocio.

\section{CONCLUSIONES}

1. La conservación y potenciación de las actividades agrarias, como medio de vida, ofrecen un balance poco alentador en conjunto. La reestructuración física de las explotaciones agrarias ha sido insuficiente. Por un lado ha disminuido el número de explotaciones pero con desigual intensidad. La evolución más positiva se ha realizado precisamente en las zonas que con antelación ya disponían de unas explotaciones mejor dimensionadas, aquellas con una vocación agrícola más marcada. En el caso del Macizo del Ernio incluso ha aumentado el número de las pequeñas explotaciones. En consecuencia no se produce un redimensionamiento económico apreciable. Las medidas de inserción de jóvenes en la agricultura tampoco han dado resultados satisfactorios, lo que repercute en un progresivo envejecimiento de los jefes de explotación a la vez que se detecta una notable falta de relevo generacional. Tampoco se ha dado una diversificación de la producción agraria, sino más bien lo contrario, con una tendencia en ambas vertientes hacia la especialización ganadera. Los mejores resultados se han producido en las iniciativas de fomento de la producción de calidad, aunque en general el porcentaje de explotaciones implicadas en este proceso es reducido.

2. La pérdida de protagonismo del sector agrario se ha querido compensar con una diversificación económica que amplíe la base productiva. Aunque en la mayoría de los macizos montañosos europeos gran parte de los esfuerzos dirigidos en esta dirección se han encaminado a la promoción del turismo, en la montaña vasca la actividad industrial ha tenido una 
presencia significativa, como reflejo de la vocación del conjunto del territorio. En efecto, se ha generado un incremento de empresas y establecimientos industriales en las áreas de estudio. En su mayor parte se trata de pequeñas empresas con una orientación productiva que reproduce su entorno industrial y en menor medida empresas ligadas a los recursos naturales de sus respectivas zonas. Hay que resaltar que buena parte de este avance se ha debido a procesos inducidos por políticas públicas de promoción industrial por medio de oferta de suelo industrial y de medidas de captación de empresas.

3. El desarrollo de los servicios ha experimentado un progreso desigual. La actividad comercial, medida en número de establecimientos, ha crecido de forma significativa en los macizos del Ernio y Gorbea, mientras que se ha retraído en la Montaña Alavesa. En el caso concreto del turismo las administraciones públicas han planificado y puesto en ejecución numerosas iniciativas de índole diversa. Fruto de ellas ha sido la notable ampliación de la oferta de alojamientos turísticos y de establecimientos de hostelería, así como de otras infraestructuras ligadas al deporte y al ocio.

En definitiva son dos las conclusiones principales. En primer lugar no puede hablarse de que los procesos de desarrollo rural centrados en el fomento de las actividades económicas hayan sido similares en todas las áreas montañosas vascas, sino que más bien se detecta con claridad un comportamiento diferenciado. En segundo lugar los logros han afectado a las actividades industriales y terciarias, pero no se han materializado en las agrarias, que siguen sufriendo una evolución negativa.

\section{BIBLIOGRAFÍA}

Berga Monge, A. (2002) 174Indicadores de desarrollo en zonas de montaña», $X V$ Simposio de Cooperativismo y Desarrollo Rural, http://cederul.unizar.es/noticias/ sicoderxv/actas.htm

Delgado, C.; Gil De ARriba, C.; Hortelano, L.A.; PlazA, J.I. (2004) «La renovación rural en los espacios de montaña: las comarcas de la vertiente norte del sector central de la Cordillera Cantábrica», en Investigaciones Geográficas, ${ }^{\circ}$ 33, 63-86.

Delgado, C.; Gil De ARriba, C.; HorTelano, L.A.; PlazA, J.I. (2007) Dinámica territorial y transformación del paisaje en la Montaña Cantábrica, Salamanca, Plaza Universitaria Ediciones.

FundaCión KALITATEA (2008) Somos lo que cuidamos. Informe 2008, Departamento de Agricultura, Pesca y Alimentación, Gobierno Vasco.

GALDÓS URRUTIA, R. (2004) «La intervención pública de la promoción de la calidad agroalimentaria: Normativa comunitaria, española y vasca», en Investigaciones Geográficas, $\mathrm{n}^{\circ}$ 34, 47-62. 
Galdós URrutia, R.; Ruiz URRestaraZU, E. (2008) «La diversidad de la montaña vasca. Ensayo de tipología para políticas territoriales», en Boletín de la Asociación de Geógrafos Españoles, no 47, 31-49.

Galdós Urrutia, R.; Porcal GonZalo, M.C.; Ruiz UrRestarazu, E. (2009) «Valoración de la dinámica demográfica reciente de los territorios de montaña del País Vasco a partir de estudio de casos», en Geographicalia, n ${ }^{\circ}$ 55, 45-69.

GobIERno VAsco (2007) Programa de Desarrollo Rural del País Vasco 2007-2013, Vitoria-Gasteiz, Departamento de Agricultura, Pesca y Alimentación.

MAitïA, F. (2006) «La montaña en la Unión Europea. Políticas y proyectos», en DElgado Viñas, C. (ed.) La montaña cantábrica. Una montaña viva, Santander, Universidad de Cantabria, Parlamento de Cantabria, 21-37.

NogALES NAHARRO, M .A. (2006) «Desarrollo rural y desarrollo sostenible: la sostenibilidad ética», en Revista de economía pública, social y cooperativa, $\mathrm{n}^{\mathrm{0}}$ 55, 7-42.

PORCAL GONZALO, M.C. (2002): «Turismo en los alojamientos rurales de Alava. El auge del agroturismo», en Aportaciones Geográficas en Homenaje al Profesor L.M. Yetano Ruiz, Zaragoza, Universidad de Zaragoza, 457-467.

PorCal Gonzalo, M.C. y ARMEnTia Pinedo, F. (2002): «Algunas iniciativas significativas encaminadas al desarrollo del turismo rural y del ecoturismo en una comarca desfavorecida del País Vasco: la Montaña Alavesa», Lurralde, n 24, 21-44.

PORCAL GonZALO, M.C. (2003): «Propuestas de actuación para el desarrollo turístico sostenible de una comarca rural de media montaña», Investigaciones Geográficas, $\mathrm{n}^{\circ} 32,65-90$.

Ruiz Urrestarazu, E.; Galdós Urrutia, R. (2008) Geografia del País Vasco, San Sebastián, Ed. Nerea. 